\title{
The Teaching Reform for Digital Image Processing As The Discipline's Basic Course
}

\author{
Yunyu Shi, Xiang Liu, Huihua Ding, Yongxiang Xia \\ School of Electronic and Electrical Engineering, Information Center \\ Shanghai University of Engineering Science \\ Shanghai, China \\ \{yunyushi, xliu, dingding, x-free \}@sues.edu.cn
}

\begin{abstract}
From the perspective of the discipline's basic course, the paper analyzes the reasons and the preliminary exploration of the teaching reform for the course "digital image processing". Some deep thoughts on the connotation, teaching content, teaching methods, teaching staff and practical teaching are put forward on the basis of the course orientation. The scheme emphasizes to elaborate concise course content for the students from several majors under the case of scattered knowledge background and limited class hours.
\end{abstract}

Keywords-digital image processing; basic courses of the discipline; teaching reform; online resources

\section{INTRODUCTION}

The content of the course digital image processing is how to use computer technology to process the digital images in particular demands, with the characteristics of strong comprehensiveness, evident interdisciplinary and in-depth integration of theories and applications [1-3]. The vast majority of colleges and universities are setting digital image processing or other related courses in the curriculum systems for electronic information, electrical, computer, automation and other subjects. At present, digital image processing is the discipline's basic course for the undergraduates in the school of electronic and electrical engineering in our university. These sophomores are come from six disciplines within four major subjects. So under this setting background, there are a series questions for the chief course teachers to think and explore deeply. Such as how to clarify the course content, accurately grasp the knowledge structure and the difficulty of focus, how to organize teaching methods, how to combine classroom teaching and experimental teaching, and so on.

\section{CURRENT SITUATION AND ORIENTATION}

Digital image processing involves many kinds of subjects and the course content is rich and varied. There are a good deal of knowledge points, including image denoising, enhancement, restoration, segmentation, feature extraction, compression coding, etc.. On the one hand, the rapid development of computer, mathematics, biology and communication technology in recent years promotes the renewal and replacement in the teaching content and teaching methods about the course digital image processing. On the other hand, according to the curriculum framework and teaching objects'

SEEE Online Courses Learning- Course Construction Project (201702003).

Shanghai College Young Teachers Training Program (ZZGCD15002). own characteristics, many teachers have been thinking and discussing about the teaching reforms. A series of curriculum construction and the optimization are carried out, such as the syllabus optimization from the point of the engineering[1], the project-driven teaching mode with special form of multi-level guidance [2], the teaching plan revising based on discussion [3] and so on, in addition to a series of experimental teaching construction work, such as the use of multi-level experimental teaching system [4], the advantages and disadvantages of different processing software in the experimental teaching[5], and experimental designs by exploring the scientific research or practical application [6].

Digital image processing is the discipline's course in our school of electrical and electronic engineering. The students are from six subjects within four first level disciplines, including computer science and technology, automation, electronic information, electrical engineering, electronic engineering, automobile radio and television etc. The curriculum background and the teaching objects of the course put forward new challenges for the teachers in our school. The past teaching methods and teaching contents are not suitable for such a wide range of professional background and the number of students, that is to say, only by using classical teaching materials, focusing on the theories and directly making experimental verification using Matlab software. Therefore, it is imperative to carry out the teaching reform for digital image processing as the discipline's basic course.

\section{DISCUSSIONS ON TEACHING REFORM}

The theories from the course digital image processing are difficult to understand to some extent and the corresponding demands are also very wide. Now the course has the characteristics of many teaching objects and multi-disciplinary in our curriculum. Therefore it is necessary to explore and discuss several aspects for the course within limited teaching hours (total 32 hours, 2 credits), such as teaching contents, teaching methods, teaching staff, practice teaching and so on.

\section{A. Teaching Contents}

Although the connections among the knowledge points are a little close in the course, the knowledge structure is not very significant. So how to accurately grasp the knowledge structure and the key points is the primary problem in the course reform for so many majors' students. 
Firstly, it should be to understand and integrate the theoretical system of digital image processing course. Especially the early professional curriculums are necessary to comprehend in order to understand the students' prior knowledge and mastered skills. And then the existing teaching contents will be selected carefully, and the connections among knowledge points will be made. Therefore, the curriculum knowledge structure is much more concise, and clear.

Secondly, the new technologies and new methods in the field of digital image processing should be absorbed based on the related scientific research achievements, and then the curriculum knowledge points could be gradually updated step by step. Full consideration is given for the transition and cohesion of knowledge orders according to the actual situation of the teaching objects, in order to emphasize the important knowledge. The research background and significance about the technologies and methods are emphatically introduced, as well as the corresponding practical application and relative merits.

Thirdly, the teaching staffs' scientific research or the application achievements should be applied in the undergraduate teaching with more specific case study on the basis of systematic knowledge structure. Therefore, it will make a transfer from the simple overlay of all knowledge points to the three-dimensional perception for the existing knowledge structure. And the students could further clarify the evolution of knowledge points from the theoretical analysis to the actual case.

\section{B. Teaching Methods}

The teaching materials should be improved based on the lesson foundation platform and the curriculum knowledge structure of digital image processing as a discipline's platform course. The teaching materials include syllabus, teaching plan, teaching arrangement, and experimental arrangement, according to the teaching objects' knowledge background in order to employ flexible teaching methods.

In terms of knowledge instruction, the knowledge background of all the teaching objects should be investigated firstly, including the previous courses and the professional expectations for this course. Therefore the teachers could clear the common basic knowledge and applications of a specific target according to their aptitude as far as possible with the basement of the requirement of the professional learning orientation.

Secondly, the knowledge database and case analysis database should be established step by step at the same time with the knowledge segmentation processing of teaching contents. And then the case database should be gradually enriched based on the guaranteed basic cases, with hierarchy multi-objective in order to cover more application background and the actual demands, which could cause the students to think about knowledge in a professional way and improve students' perceptual cognition on the application of all these knowledge.

Again, the domestic and foreign online teaching resources could be referenced, such as "Image and Video Processing:
From Mars to Hollywood with A Stop at The Hospital" by duke university launched on MOOC website. And modern education technologies are applied in the processing of knowledge interpretation. The proportion of knowledge explaining and content discussing is allocated rationally, assisted by multimedia teaching situation to verify a large number of examples. The WYSIWYG teaching way could mobilize the students' initiative and gradually form an open teaching atmosphere.

\section{Teaching Staff}

Digital image processing, as a discipline basic course, puts forward new requirements and challenges for lecturers. Thus it is necessary to improve the teaching team construction, allocate the teaching staff reasonably, and provide more chances to discuss teaching experience.

Taken as a whole, the age structure of the teachers is reasonable, covering the old, middle-aged and young teachers. Most of them have a doctoral degree or rich business experience, and their respective research topics are around computer vision, digital media or other related areas, with the corresponding support of national, provincial and so level scientific research projects.

Especially, the young and middle-aged teachers are committed to the cultivation of the scientific research ability in addition to the course teaching and the related course construction work. Therefore in order to introduce new technology and new methods in the traditional teaching contents, the scientific research or the application achievements could feedback in the undergraduate teaching, and combine the teaching contents and the forefront development.

At present, the teachers are respectively from several teaching teams based on the teaching team construction in our school, such as programming design basis team, computer software curriculum group team and digital communication and signal processing team, which are closely related to the teaching content of digital image processing. Accordingly, it can be explained that digital signal processing theory is the source of digital image processing technology, and the integrated software and hardware for the digital image processing system is the comprehensive target.

\section{Practice Teaching}

As is known to all, digital image processing is a practical course. The application of knowledge, and the specific combination of theoretical knowledge and practical application should be especially emphasized in the curriculum processing. The case analysis library is taken as the core to make every level knowledge concrete, vivid and visualization. So the students could further clear the course's role in the whole course system through hands-on experiments to verify the theory content and corresponding objective analysis and intuitive perception.

The specific contents of experimental teaching need to be updated on the basis of the carefully established experimental case database in the early stage and the feedback from the teachers' scientific research, in order to strengthen the 
connection and the flexibility among the experiment contents. The difficulty of all experimental contents could be increased in a gradual way. The depth and breadth of these contents will be guided to set extension experiment contents by the professional demands so that to lay a solid foundation for subsequent courses.

Generally, the practice teaching is closely linked in the process of classroom teaching rather than in the latter half scheduling to further improve the combination between the practice experiments and theoretical contents. The experimental scheme will be planned in time, and the feedback results could be obtained by computer programming practice. The students could verify the theory content and master the basic knowledge system through the implementation of several typical algorithms.

Moderately difficult computer programming language and platform for digital image processing experiments should be selected for these undergraduate students from multiple professional backgrounds. Basically, all the students are with $\mathrm{C}$ language programming basis. But it is complex to realize digital image processing algorithms with $\mathrm{C}$ language and then to greatly increase the difficulty degree in learning this course. Therefore Matlab software is adopt in the experimental teaching, and the example algorithms in case analysis database are provided correspondingly.

\section{IMPLEMENTATION PROGRESS AND INITIAL EFFECT}

\section{A. Curriculum Connotation Reconfirmation and Main Points Decomposition}

The curriculum connotation is further clarified based on the early research on knowledge background of teaching objects. For different professional demands, the internal relationship among different courses is strengthened and the wide application is also verified. Take the students of electronic information as an example; they are relatively easy to understand the image frequency domain transform due to the basis of digital signal processing. It is efficient to eliminate the barriers among these professionals and then encourage the communication and cooperation of these students.

The book Image Engineering (I): Image Processing published by Tsinghua University press [7] is selected as the textbook in the course progress. And then the teaching plan is revised and the key points of teaching contents are determined based on the curriculum connotation, combined with the students' practical needs. Therefore, the teaching database construction of digital image processing is gradually improved.

For updating the knowledge structure, except fully considering the knowledge framework, the contents are organized in a gradual forward way, which is from knowledge point, knowledge line, and knowledge facet to final knowledge network. So a multi-level multi-objective teaching system is established, and the key points are adjusted according to the actual needs of the students.

In the teaching processing, the teaching method of point breakthrough is used, that is to say, one or two typical problems are explained in detail for every part of independent content. The advantage of this method is that it's easy to find the entrance to the knowledge space and then to connect other related knowledge. With the assistance of case studies, the students could further understand the nature of the leaned knowledge. At the same time, the relationship between the chapters should be paid attention and to tackle with the content redundancy scattered in the knowledge structure.

Multimedia equipment and other resource are fully used to carry out the teaching processing. The teaching materials are developed by several software tools for explaining the key points. Especially, graphics and animation simulation could demonstrate the content that is hard to understand just by text description, such as Fourier Transform.

\section{B. Online Resources and Frontier Research Introduction}

Before carrying out the curriculum, the teachers have been finding the online courses related with digital image processing from the website MOOC, China University MOOC and so on. These online courses are recommended to the students for watching after class time and the topic seminars are regularly held during the class processing. For example about image denoising or edge extraction, the students could be able to understand the different expression and different application background combining with the classroom knowledge.

At the same time, the scientific research progress and advanced technologies, the teachers' research achievements are properly introduced into the class besides just explaining the classic theoretical knowledge, such as the research on image quality objective assessment, image efficient compression, and so on. The students could be guided gradually to carry out extracurricular studies and then understand the knowledge development and promotion, which is useful for their further scientific research or project planning with the learned knowledge.

Direct research-discussion teaching is not appropriate because of so many students, which is prone to go off subject. The heuristic teaching method and discussion teaching method are both adopt in the introduction of network resources and advanced technologies. Therefore the multi-level grouping research discussion is practiced. Sometimes the teacher gives a heuristic problem in the class, combining with the classroom discussion, which could be carried out in the last ten minutes of some classes. At the same time, the teachers can listen to the students' views, and achieve feedback from the students in order to ensure the teaching quality.

\section{Learning Effect Verification and Practical Course Extension}

The students' active feedback has proved the learning effect to a certain extent in the course process. Full consideration about the knowledge is the right way to master the principle, to insight into the nature, and then to construct their own knowledge network. On the other hand, traditional classroom questioning and homework correction could also provide an auxiliary means of learning effect verification and ensure the students' understanding about the classroom knowledge. The ability of students' active thinking could be reflected by their extracurricular learning about the lasted technologies in the 
field of digital image processing, such as deep learning technology, which will be discussed before the end of the course. The students' enthusiasm, and their interest and potential could be mobilized effectively.

The combination of theoretical teaching and experimental teaching is ensured during the practical teaching. The content of the experimental teaching covers the knowledge of the pre class on the basis of careful plan. Five experimental topics and a number of corresponding procedure examples are designed and prepared based on Matlab within limited hours, which could form a digital image processing system framework. Generally, the students reflect that they could give more focus on the understanding and analysis of the digital image processing algorithms based on Matlab basic grammar and basic functions, and their confidence in the algorithm designing is enhanced. The extension of practical courses is ensured by the multi-level experimental setting and the requirements from the practical application, which could encourage the students to carry out project analysis and algorithm development.

\section{CONCLUSION}

Digital image processing is the discipline's course in our school of electrical and electronic engineering, with the characteristics of large number of students, scattered background, limited hours, and so on, which put forwards new challenges for the teachers. Based on the unique curriculum settlement, the paper gives the deep thoughts on the teaching contents, teaching methods, teaching staff, and practice teaching respectively. More important, the clarified curriculum connotation, the accurate knowledge structure and the key points, the introduction of advanced teaching ideas, the verification of the students' learning effect, and the extension of the experimental teaching contents, are elaborated and discussed in detail. Recent progress of the course shows that these preliminary attempts could adapt to the current curriculum settlement and basically meet the students' needs from several majors.

\section{REFERENCES}

[1] Weihong Ma, Jinping Ni, and Hui Tian, "Exploration and Practice on Teaching Content Optimization of Digital Image Processing Course," China Electric Power Education. Bejing, no. 31, pp. 99-100, 2011(In Chinese).

[2] Yaxun Zhou, Wei Jin, "Practice of Project Driven Teaching Mode in Digital Image Processing Course," China Electric Power Education. Bejing, no. 7, pp. 82-83, 2010(In Chinese).

[3] Haifang Zhou, "Study-discussion Teaching Method in Courses of Digital Image Processing," Computer Education. Bejing, no. 18, pp. 7477, 2011(In Chinese).

[4] Chu He, Qian Feng, and Fang Yang, "The Design of the Teaching Process of Digital Image Processing," Computer Education. Bejing, no. 24, pp. 93-97, 2010 (In Chinese).

[5] Jun Bai, Hongmei Yan, and Ming Zhang, "Analyses of Advangtage and Disadvantage for Matlab on Teaching Digital Image Process Course," Journal of EEE. Nanjing, vol. 32, no. 2, pp. 82-83, 2010(In Chinese).

[6] Junhua Liang, Yang Liu, Zhisheng Zhao and Jing Li, "Teaching Reform and Exploration based Research-oriented for Digital Image Processing," Journal of Jiamusi Vocational Institute. Jiamusi, no. 11, pp. 175-176, 2016(In Chinese).

[7] Yujin Zhang, Image Engineering (I): Image Processing, 3rd ed., Beijing: Tsinghua University Press, 2012(In Chinese). 